\title{
Synthesis and Characterization of Fenugreek Gum Carbamate
}

\author{
A.A. Ragheb, A.A. Abd EL- Rahman, M.A. Ibrahim*, \\ I. Abd EL- Thalouth and A.R. Abd Al- Moaty ${ }^{* * *}$ \\ National Research Center, Dokki, Giza, ${ }^{*}$ Faculty of Applied \\ Arts, Helwan University and ${ }^{* *}$ High Institute of Applied Arts \\ and Design Academy, Cairo, Egypt.
}

\begin{abstract}
ALACTOMANNAN gum was isolated from fenugreek seeds I and subjected to react with urea at high temperature in the solid state. The obtained carbamate derivatives were purified via dissolution in water, filtration followed by extraction in Soxlet using $75 \%$ ethylalcohol. The purified products were evaluated via measuring the solubility, nitrogen content and rheological properties. The nitrogen content increases from 1.45 to 4.13 by increasing the amount of urea from 20 to $100 \mathrm{~g} / 100 \mathrm{~g}$ of the dry gum. The solubility of the carbamate derivatives in water was found to be depending on the extent of reaction expressed as \% N. Samples acquire $1.45 \% \mathrm{~N}$ or less is soluble in water, while those contain higher $\% \mathrm{~N}$ are insoluble in water but soluble in $1 \%$ sodium hydroxide solution. All of the samples are characterized by nonNewtonian pseudoplastic behaviour regardless of the $\% \mathrm{~N}$, the storing time or the solvent used and their apparent viscosity at any specific rate of shear was found to be depending on its nitrogen content. Evaluation of these derivatives as thickening agents in textile printing will be published in another article.
\end{abstract}

Fenugreek is an annual legume, it is one of the few legumes that retains its endosperm. The endosperm of fenugreek is a gum that surrounds the seed (the embryo and cotyledons). The endosperm contains high amounts of galactomannan, which is used as thickening agent in the food and textile industry ${ }^{(1)}$.

The galactomannan in fenugreek consists of one molecule of galactose and one molecule of mannose, giving it somewhat different chemical and functional properties than guar gum ${ }^{(2,3)}$.

Recently in our laboratory galactomannan gum was isolated from several plant seeds and subjected to chemical modification ${ }^{(4-8)}$. To our knowledge no systematic study has been carried out, so far, on carbamation of fenugreek gum. Modification of fenugreek gum by reacting it with urea would yield essentially fenugreek gum carbamate derivative which may find several applications in textile chemical teclnology. 
Hence, the current work presents a thorough investigation into synthesis and characterization of fenugreek gum carbamate derivatives. Implementation of such derivatives in printing cotton fabries will be published in another paper.

\section{Materials}

\section{Experimental}

Plant seeds

Clean, dry fenugreek seeds cultivated in Egypt, purchased from the local market was used as a raw material in the present work.

\section{Extraction of the gum}

For the separation of the galactomannan gum from fenugreek seeds; the endosperm was thoroughly separated from the hull and germ. This was carried out mechanically; where the three components of the seeds, namely hull, endosperm and germ differ in their hardness properties like the guar seeds; the procedure adopted was carried out as follows:

The clean, dry fenugreek seeds were grounded under mild conditions using a laboratory mixer. The grounded seeds were then sieved to remove the germ which possesses the lowest hardness. The remaining part was soaked over night in water, to allow the gum to swell. The swelled gum was separated from the other components of the seeds via filtration through a muslin cloth.

The separated gum was either used as it is, i.e. in the viscous form or precipitated using comercial ethyl alcohol, dired and finally grinded to fine powder.

\section{Carbamation}

The extracted dry fenugreek gum was allowed to react using the solid state technique ${ }^{(9)}$ as follows:

Fenugreek gum and urea $(5: 1),(5: 2),(5: 3),(5: 4)$ and $(5: 5)$ were mixed well in the solid state in a laboratory mortar. The mixture was transferred to porcelain crucible then subjected to high temperature $\left(165^{\circ} \mathrm{C}\right)$ for $60 \mathrm{~min}$.

Furthermore, another 3 samples were prepared at the ratio $(5: 1)$ dry gum urea: for 20,40 and $60 \mathrm{~min}$. At this end the thermally treated mixtures were dissolved in distilled water at room temperature precipitated with ethyl- alcohol, filtered on a sintered glass funnel and washed several times with $85 \%$ ethyl alcohol to ensure complete removal of unreacted urea. Finally the treated gum precipiteated was dried in a desiccators containing calcium chloride, and analyzed for nitrogen.

\section{Analysis and measurements}

\section{Determination of nitrogen content}

Nitrogen content of the prepared fenugreek carbamate gum derivatives (expressed as $\mathrm{N} \%$ ) was determined using the microkjedahl method ${ }^{(10)}$.

Egypt. J. Chem. 58, No. 4 (2015) 
Measurement of the the rheological properties of the pastes

The rheological properties of prepared derivatives pastes were mearured using a rotary viscometer (Rheomat -15 zurich Switzerland ${ }^{(11)}$.

The corresponding apparent viscosity was calculated according to the following equation:

$$
\eta=T / D
$$

where: $\eta$ is the apparent viscosity in poise

$\mathrm{T}$ is the shearing stress $\left(\right.$ dyne $-\mathrm{cm}^{-2}$ )

$\mathrm{D}$ is the rate of shear $\left(\mathrm{S}^{-1}\right)$

\section{Results and Discussion}

As previously mentianed the min aim of the present work is to senthesis, characterize and utilize fenugreek carbamate derivatives to be used as thickeners in direct and discharge printing styles. To achieve this goal galactomannan gum was isolated from fenugreek seeds. The isolated gum was precipitated using commercial ethyl alcohol, dried and finally grinded to a fine powder. After that the gum was subjected to react with urea using different amount $(20,40,60,80$ and $100 \mathrm{~g} / 100 \mathrm{~g}$ of the dry gum $)$ at high temperature $\left(165^{\circ} \mathrm{C}\right)$ for 60 minutes. The reaction can be represented as follows ${ }^{(12,13)}$.

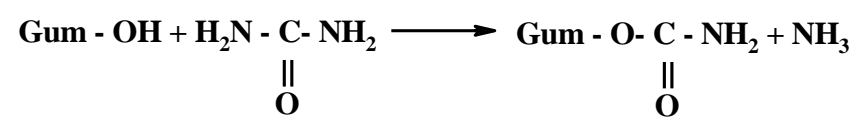

After the necessary purification, the modified fenugreek gum samples were analyzed for nitrogen, (which is an indication of the degree of carbamate substitution in the gum molecules), and its influence on solubility was investigated - the results obtained are given in Table 1.

TABLE 1. Effect of urea concentration on percent nitrogen content and on the solubility of the obtained carbamate derivatives.

\begin{tabular}{|c|c|c|c|}
\hline \multirow{2}{*}{$\begin{array}{c}\text { Amount of urea g/100g } \\
\text { of dry gum }\end{array}$} & \multirow{2}{*}{$\mathbf{N}$} & \multicolumn{2}{|c|}{ Solubility in } \\
\cline { 3 - 4 } & & Water & $\mathbf{1 \%}$ NaOH Solution \\
\cline { 3 - 4 } & 0 & Soluble & Soluble \\
\hline 0 & 1.453 & Insoluble & Soluble \\
\hline 40 & 2.062 & Insoluble & Soluble \\
\hline 60 & 2.307 & Insoluble & Soluble \\
\hline 80 & 3.160 & Insoluble & Insoluble \\
\hline 100 & 4.126 & Insoluble & Insoluble \\
\hline
\end{tabular}

The reaction was conducted at $165^{\circ} \mathrm{C}$ for $60 \mathrm{~min}$. 
The data in Table 1 indicate that, the amount of urea plays a dominate role in the extent of reaction between fenugreek gum and urea, where the reaction increases regularly by increasing the amount of urea from 20 to $100 \mathrm{~g} / 100 \mathrm{~g}$ gum (the nitrogen content expressed as N\% increased from 1.45 to $4.13 \%$ ).

It is also clear from the data that, the treatment with urea under the previous conditions converted the gum to the insoluble state in water.

But in state of using $1 \% \mathrm{NaOH}$, the fenugreek gum carbamate became soluble on using urea up to $60 \mathrm{~g} / 100 \mathrm{~g}$ gum (Table 1 ).

Further increase in the amount of urea more than $60 \mathrm{~g}$; i.e. 80 and $100 \mathrm{~g}$ converted the product to be insoluble in water, due to increase in the carbamoyl groups which can be hydrolyzed by sodium hydroxide to convert the carbamoyl group to carboxyl group and increase the solubility of the prepared gum.

Based on the previous investigation and to obtain water soluble derivatives, the effect of reaction time $(20,40$ and $60 \mathrm{~min})$ with urea at the smallest concentration $(20 \mathrm{~g})$ was studied. The results obtained are given in Table 2.

TABLE 2. Effect of reaction time of fenugreek gum/ urea reaction product* on N\% and on solubility of the products.

\begin{tabular}{|c|c|c|c|}
\hline \multirow{2}{*}{$\begin{array}{c}\text { Reaction time } \\
\left(\mathbf{a t ~} \mathbf{1 6 5}^{\mathbf{}} \mathbf{C}\right)\end{array}$} & \multirow{2}{*}{$\mathbf{N \%}$} & \multicolumn{2}{|c|}{ Solubility in } \\
\cline { 3 - 4 } & & Water & $\mathbf{1 \%} \mathbf{\text { NaOH Solution }}$ \\
\hline $0 \mathrm{~min}$ & 0 & Swelled & Soluble \\
\hline $20 \mathrm{~min}$ & 0.592 & Soluble & Soluble \\
\hline $40 \mathrm{~min}$ & 0.740 & Soluble & Soluble \\
\hline $60 \mathrm{~min}$ & 1.453 & Insoluble & Soluble \\
\hline
\end{tabular}

- The amount of urea was $20 / 100 \mathrm{~g}$.

It is clear from the data of Table 2 that all the products obtained on using $20 \mathrm{~g}$ urea $/ 100 \mathrm{~g}$ dry gum are water soluble except the sample prepared at $60 \mathrm{~min}$.

But in state of using $1 \% \mathrm{NaOH}$, the fenugreek gum carbamate became solubled on using urea up to $60 \mathrm{~g} / 100 \mathrm{~g}$ gum (Table 1 ).

Further increase, in the amount of urea more than $60 \mathrm{~g}$; i.e. 80 and $100 \mathrm{gm}$ converted the product to be insoluble in water.

\section{Rheolgoical properties}

To investigate the effect of the presence of carbamate groups in fenugreek gum molecules on the rheological properties of the products, pastes at a concentration of $6 \%$ were prepared either in water or $1 \%$ sodium hydroxide solution and the rheological properties of the obtained pastes were measured using Rheomat -15 . The results obtained for the freshly prepared pastes and after storing for $24 \mathrm{hr}$ are represented in Fig. 1-5.

Egypt. J. Chem. 58, No. 4 (2015) 


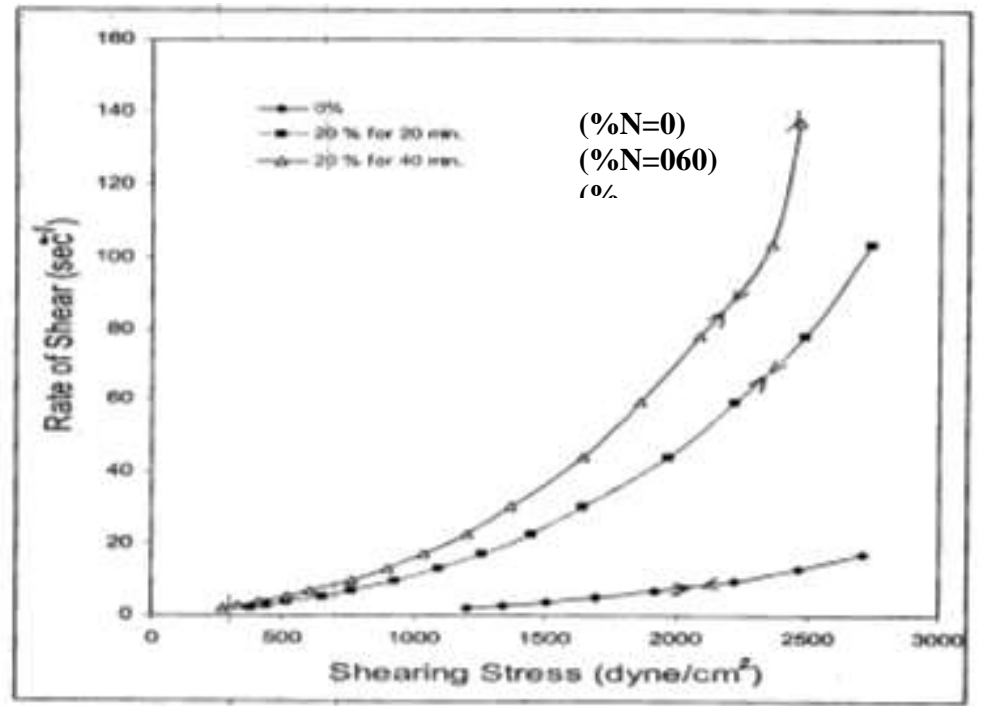

Fig. 1. Effect of urea concentration \& reaction time on the apparent viscosity of carbamated fenugreek glactomannan gum $(6 \%)$ at different rates of shear (freshly prepared).

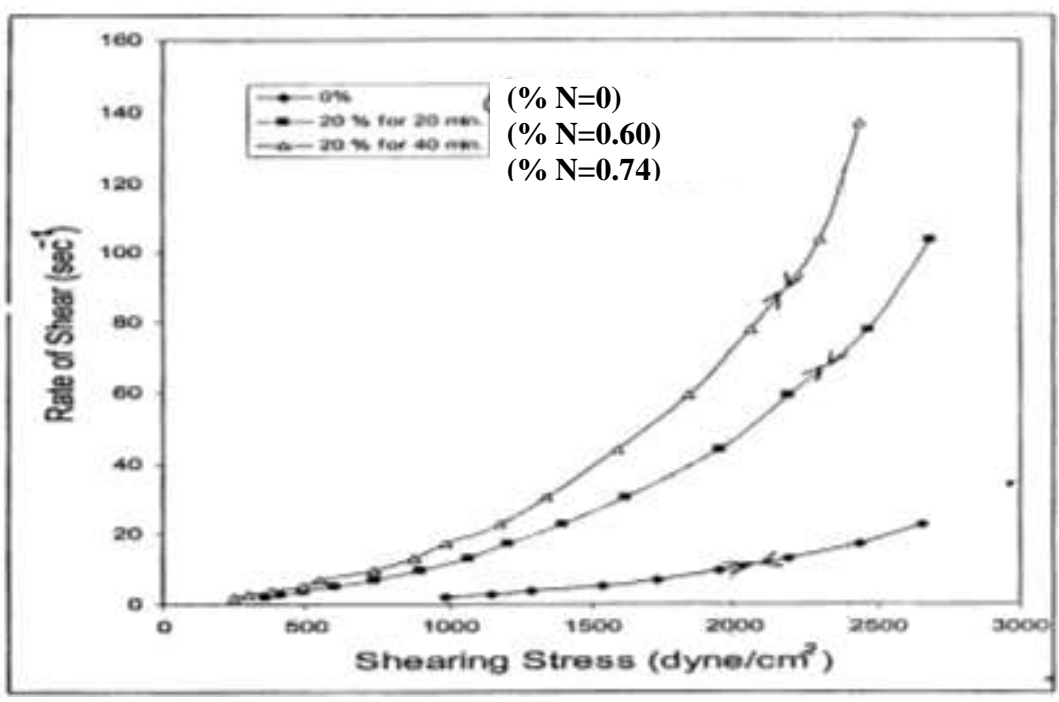

Fig. 2. Effect of urea concentration \& reaction time on the apparent viscosity of carbamated fenugreek glactomannan gum $(6 \%)$ at different rates of shear (after $24 \mathrm{hr}$ storing). 


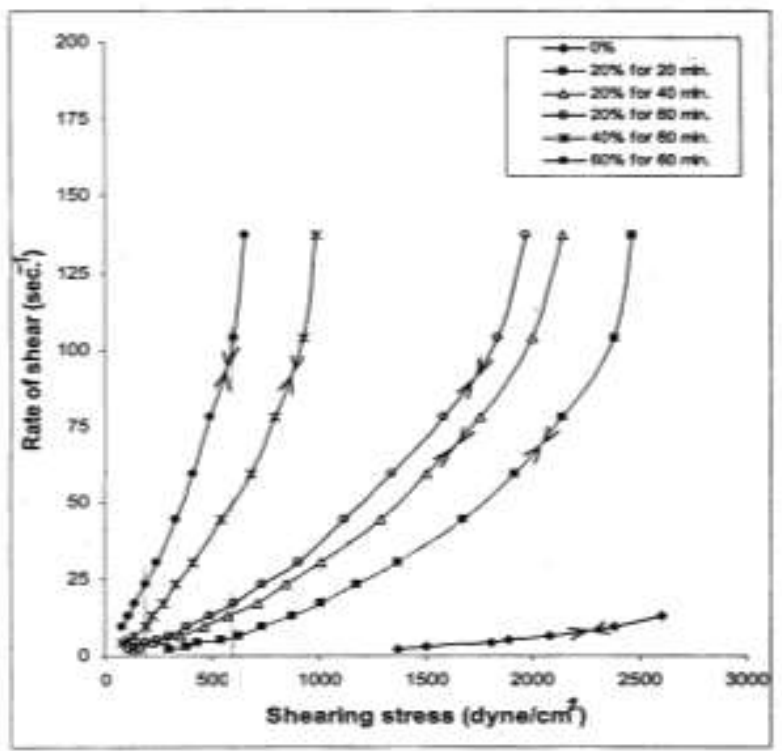

Fig. 3. Effect of urea concentration \& reaction time on the apparent viscosity of carbamated fenugreek galactomannan gum $(6 \%)$ at different rates of shear (freshly prepared).

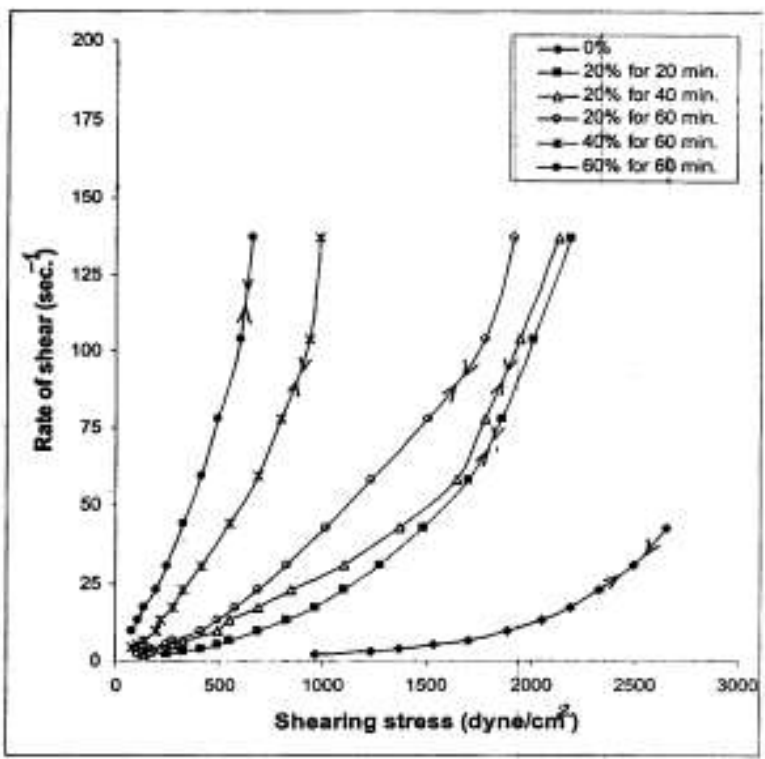

Fig. 4. Effect of urea concentration \& reaction time on the apparent viscosity of carbamated fenugreek galactomannan gum (6\%) treated with $\mathrm{NaOH}(1 \%)$ at different rates of shear (after $24 \mathrm{hr}$ storing).

Egypt. J. Chem. 58, No. 4 (2015) 


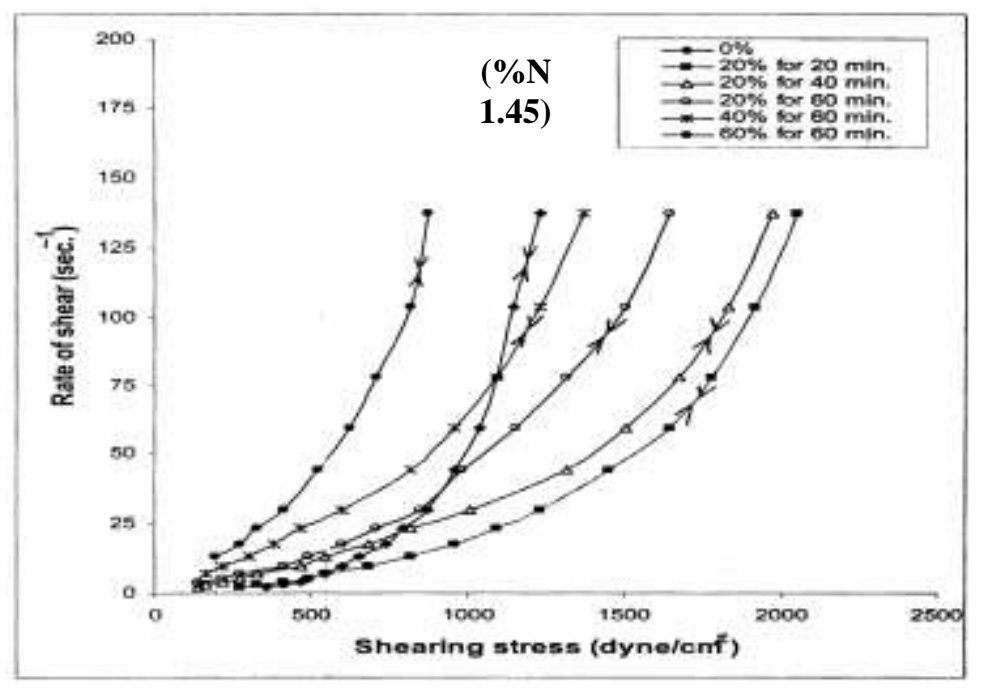

Fig. 5. Effect of urea concentration \& reaction time on the apparent viscosity of carbamated fenugreek galactomannan gum $(6 \%)$ treated with $\mathrm{NaOH}(1 \%)$ at different rates of shear (after 3 days. storing).

Figures 1 and 2 represent the rheological properties of the untreated and carbamate gum derivatives which acquire $\% \mathrm{~N}$ of 0.592 and 0.74 dissolved in water. The results signify that all the pastes before and after modification for the freshly prepared or after storing the pastes for $24 \mathrm{hr}$ are characterized by non Newtonian pseudoplastic behaviour since the rheogams are not linear and the up and down flow curves are concident. However, the location of the theograms with respect to the rate of shear axis depends on the degree of modification. As the $\% \mathrm{~N}$ increases the rheogram is shifted far from the rate of shear axis indicating an increase in the apparent viscosity as it is clear from Table 2. Storing of the pastes for $24 \mathrm{hr}$ has practically no influence on the rheological characterestic of these pastes.

It is also clear from Fig. 4-5 that, pastes prepared from fenugreek gum carbamate samples of different $\mathrm{N} \%$ dissolved in $1 \%$ sodium hydroxide solution also still characterised by non- Newtonian pseudoplastic behaviour as the original pure fenugreek gum pastes. It is also observed that, the values of the shearing stress decrease regularly as the degree of substitution, expressed as N\% increases. And in all cases of fenugreek gum carbamate samples the shearing stress values decrease by increasing storing time. This means that the presence of carbamate groups has a remarkable effect on the apparent viscosity of their pastes as it is clear from the tables of viscosity. 
Apparent viscosity

The apparent viscosity of the aforementioned pastes was calculated from the values of shearing stress and rate of shear. The obtained data are given in Tables 3-7.

Generally speaking, it is clear from the data that, upon increasing the applied rate of shear on the thickener pastes, their apparent viscosity decreases. Furthermore; it is clear from the data that, at a given rate of shear the apparent viscosity of fenugreek gum carbamate depends on the concentration of urea used in the preparation of the carbamate derivative, where it decreases as the concentration of urea increases.

For example from Table 5 at rate of shear $6.779\left(\mathrm{sec}^{-1}\right)$ the apparent viscosity decrease from 44.428 to 24.233 poise as the urea concentration increase from 20 to $40 \%$. The decrease in the apparent viscosity of fenugreek gum carbamate samples by increasing urea concentration may be due to the thermal hydrolytic cleavage of fenugreek gum molecules by increasing urea concentration at $165^{\circ} \mathrm{C}$. The hydrolytic cleavage of fenugreek gum molecules causes the formation of lower molecular weight products which acquire relatively lower apparent viscosity.

On comparing Tables 5, 6 and 7. It is clear that storing of these pastes in accompanied by a decrease in their apparent viscosity. However the presence of carbamate groups on fenugreek galactomannan gum increases the stability of these pastes for storing. Since the \% decrease in the apparent viscosity of the original gum is relatively higher than the modified gum.

TABLE 3. Effect of urea concentration \& reaction time on the apparent viscosity of carbamated fenugreek galactomannan gum $(6 \%)$ at different rates of shear (freshly prepared).

\begin{tabular}{|c|c|c|c|}
\hline \multirow{2}{*}{$\begin{array}{c}\text { Rate shear } \\
\left(\text { sec. }^{-1}\right)\end{array}$} & \multicolumn{4}{|c|}{ Apparent viscosity in poise on using Urea concentration at: } \\
\cline { 2 - 4 } & $\begin{array}{c}\text { Untreated } \\
\text { sample }\end{array}$ & $\begin{array}{c}\text { 20\% Urea Treated for } \\
\text { 20min }\end{array}$ & $\begin{array}{c}\text { 20\% Urea Treated for } \\
\text { 40min }\end{array}$ \\
\hline 2.180 & 552.623 & 175.834 & 125.596 \\
\hline 2.927 & 458.360 & 149.668 & 112.251 \\
\hline 3.851 & 391.041 & 135.086 & 106.647 \\
\hline 5.139 & 330.328 & 127.869 & 101.229 \\
\hline 6.779 & 282.726 & 113.090 & 88.856 \\
\hline 9.771 & 226.975 & 95.273 & 78.480 \\
\hline 13.12 & 187.820 & 83.475 & 68.867 \\
\hline 17.26 & 157.046 & 72.971 & 60.280 \\
\hline 23.03 & - & 63.010 & 52.130 \\
\hline 30.380 & - & 54.075 & 45.062 \\
\hline 44.100 & - & 44.702 & 37.251 \\
\hline 59.220 & - & 37.449 & 31.439 \\
\hline 77.920 & - & 31.976 & 26.705 \\
\hline 103.90 & - & 26.352 & 22.662 \\
\hline 137.10 & - & - & 17.973 \\
\hline
\end{tabular}

Egypt. J. Chem. 58, No. 4 (2015) 
TABLE 4. Effect of urea concentration \& reaction time on the apparent viscosity of carbamated fenugreek galactomannan gum $(6 \%)$ at different rates of shear (after 24hr storing).

\begin{tabular}{|c|c|c|c|}
\hline \multirow{2}{*}{$\begin{array}{c}\text { Rate shear } \\
\left(\mathbf{s e c}^{-\mathbf{1}} \mathbf{)}\right.\end{array}$} & \multicolumn{3}{|c|}{ Apparent viscosity in poise on using Urea concentration at: } \\
\cline { 2 - 4 } & $\begin{array}{c}\text { Untreated } \\
\text { sample }\end{array}$ & $\begin{array}{c}\text { 20\% Urea Treated for } \\
\text { 20min }\end{array}$ & $\begin{array}{c}\text { 20\% Urea Treated for } \\
\text { 40min }\end{array}$ \\
\hline 2.180 & 452.146 & 163.275 & 113.036 \\
\hline 2.927 & 392.880 & 140.314 & 102.897 \\
\hline 3.851 & 334.162 & 127.977 & 99.537 \\
\hline 5.139 & 298.361 & 117.213 & 95.901 \\
\hline 6.779 & 254.453 & 109.051 & 80.778 \\
\hline 9.771 & 198.954 & 92.471 & 75.658 \\
\hline 13.12 & 166.951 & 81.376 & 66.780 \\
\hline 17.26 & 141.183 & 69.798 & 57.107 \\
\hline 23.03 & 115.321 & 60.663 & 51.122 \\
\hline 30.380 & - & 53.173 & 44.161 \\
\hline 44.100 & - & 44.081 & 36.009 \\
\hline 59.220 & - & 36.987 & 31.129 \\
\hline 77.92 & - & 31.624 & 26.353 \\
\hline 103.90 & - & 25.825 & 22.135 \\
\hline 137.10 & - & - & 17.774 \\
\hline
\end{tabular}

TABLE 5. Effect of urea concentration \& reaction time on the apparent viscosity of carbamated fenugreek galactomannan gum $(6 \%)$ treated with $\mathrm{NaOH}$ (1\%) at different rates of shear (Fresh).

\begin{tabular}{|c|c|c|c|c|c|c|}
\hline \multirow{2}{*}{$\begin{array}{c}\text { Rate } \\
\text { shear } \\
\left(\text { sec. }^{-1}\right)\end{array}$} & \multicolumn{6}{|c|}{ Apparent viscosity in poise via using carbamation concentration at: } \\
\hline & $0 \%$ & $\begin{array}{c}20 \% \\
\text { for } 20 \mathrm{~min}\end{array}$ & $\begin{array}{c}20 \% \\
\text { for } \mathbf{4 0} \mathrm{min}\end{array}$ & $\begin{array}{c}20 \% \\
\text { for } 60 \mathrm{~min}\end{array}$ & $\begin{array}{c}40 \% \\
\text { for } 60 \\
\text { min }\end{array}$ & $\begin{array}{c}60 \% \\
\text { for } 60 \mathrm{~min}\end{array}$ \\
\hline 2.180 & 627.981 & 138.155 & 62.798 & 50.238 & - & - \\
\hline 2.927 & 514.485 & 130.960 & 56.125 & 47.950 & - & - \\
\hline 3.851 & 469.249 & 113.757 & 56.878 & 49.768 & - & 28.439 \\
\hline 5.139 & 367.624 & 106.557 & 53.278 & 46.771 & - & 26.639 \\
\hline 6.779 & 306.959 & 92.895 & 52.506 & 44.428 & 24.233 & 24.233 \\
\hline 9.771 & 243.788 & 75.658 & 47.636 & 39.230 & 22.416 & 21.399 \\
\hline 13.12 & 198.254 & 66.780 & 43.824 & 37.564 & 22.955 & 22.208 \\
\hline 17.26 & - & 58.694 & 41.244 & 34.899 & 22.208 & 20.868 \\
\hline 23.03 & - & 51.122 & 36.855 & 32.099 & 20.211 & 19.615 \\
\hline 30.380 & - & 45.062 & 33.346 & 29.741 & 19.827 & 18.025 \\
\hline 44.100 & - & 37.872 & 29.180 & 25.455 & 18.625 & 15.521 \\
\hline 59.220 & - & 32.364 & 25.428 & 22.654 & 16.182 & 13.870 \\
\hline 77.920 & - & 27.408 & 22.488 & 20.380 & 14.055 & 12.298 \\
\hline 103.90 & - & 22.926 & 19.237 & 17.656 & 11.858 & 10.540 \\
\hline 137.10 & - & 17.973 & 15577 & 14.378 & 9.985 & 8.188 \\
\hline
\end{tabular}


TABLE 6. Effect of urea concentration \& reaction time on the apparent viscosity of carbamated fenugreek galactomannan gum $(6 \%)$ treated with $\mathrm{NaOH}$ (1\%) at different rates of shear (after $24 \mathrm{hr}$ storing).

\begin{tabular}{|c|c|c|c|c|c|c|}
\hline \multirow{2}{*}{$\begin{array}{c}\text { Rate } \\
\text { shear } \\
\left(\text { sec. }^{-1}\right)\end{array}$} & \multicolumn{6}{|c|}{ Apparent viscosity in poise via using carbamation concentration at: } \\
\hline & $0 \%$ & $\begin{array}{c}20 \% \\
\text { for } 20 \mathrm{~min}\end{array}$ & $\begin{array}{c}20 \% \\
\text { for } 40 \mathrm{~min}\end{array}$ & $\begin{array}{c}20 \% \\
\text { for } 60 \mathrm{~min}\end{array}$ & $\begin{array}{c}40 \% \\
\text { for } 60 \mathrm{~min}\end{array}$ & $\begin{array}{c}60 \% \\
\text { for } 60 \mathrm{~min}\end{array}$ \\
\hline 2.180 & 439.587 & 125.596 & 62.798 & 50.238 & - & - \\
\hline 2.927 & 420.942 & 112.251 & 56.878 & 47.950 & 46.771 & - \\
\hline 3.851 & 355.492 & 106.647 & 56.125 & 46.771 & 35.549 & - \\
\hline 5.139 & 298.361 & 95.901 & 53.278 & 42.659 & 26.639 & - \\
\hline 6.779 & 250.414 & 80.778 & 50.439 & 42.032 & 20.194 & - \\
\hline 9.771 & 193.349 & 70.054 & 48.467 & 40.389 & 19.615 & - \\
\hline 13.12 & 156.516 & 62.606 & 41.737 & 378.564 & 18.782 & 14.608 \\
\hline 17.26 & 126.906 & 55.521 & 39.658 & 33.312 & 17.449 & 15.86 \\
\hline 23.03 & 101.055 & 47.555 & 36.855 & 29.772 & 16.644 & 14.226 \\
\hline 30.380 & 82.013 & 40.556 & 36.050 & 27.037 & 15.321 & 13.518 \\
\hline 44.100 & 60.223 & 31.043 & 31.043 & 22.971 & 12.416 & 10.554 \\
\hline 59.220 & - & 25.981 & 27.740 & 20.805 & 11.096 & 10.171 \\
\hline 77.920 & - & 21.785 & 22.840 & 19.362 & 10.190 & 9.136 \\
\hline 103.90 & - & 18.446 & 18.710 & 17.128 & 9.223 & 7.905 \\
\hline 137.10 & - & 15.976 & 15.577 & 13.979 & 7.189 & 6.390 \\
\hline
\end{tabular}

TABLE 7. Effect of urea concentration $\&$ reaction time on the apparent viscosity of carbamated fenugreek galactomannan gum $(6 \%)$ treated with $\mathrm{NaOH}$ (1\%) at different rates of shear (after $3 \mathrm{hr}$ storing).

\begin{tabular}{|c|c|c|c|c|c|c|}
\hline \multirow{2}{*}{$\begin{array}{c}\text { Rate } \\
\text { shear } \\
\left(\text { sec. }^{-1}\right)\end{array}$} & \multicolumn{6}{|c|}{ Apparent viscosity in poise via using carbamation concentration at: } \\
\hline & $\mathbf{0 \%}$ & $\begin{array}{c}20 \% \\
\text { for } 20 \mathrm{~min}\end{array}$ & $\begin{array}{c}20 \% \\
\text { for } \mathbf{4 0} \mathrm{min}\end{array}$ & $\begin{array}{c}20 \% \\
\text { for } 60 \mathrm{~min}\end{array}$ & $\begin{array}{c}40 \% \\
\text { for } 60 \mathrm{~min}\end{array}$ & $\begin{array}{c}60 \% \\
\text { for } 60 \mathrm{~min}\end{array}$ \\
\hline 2.180 & 163.275 & 125.596 & 62.798 & - & - & - \\
\hline 2.927 & 140.314 & 112.251 & 56.878 & 46.771 & - & - \\
\hline 3.851 & 120.867 & 106.647 & 56.125 & 42.623 & 21.329 & - \\
\hline 5.139 & 95.901 & 95.901 & 53.278 & 42.032 & 21.311 & - \\
\hline 6.779 & 80.778 & 80.778 & 48.468 & 40.389 & 20.218 & - \\
\hline 9.771 & 61.647 & 70.545 & 47.636 & 37.564 & 19.615 & 8.406 \\
\hline 13.12 & 50.085 & 62.606 & 41.737 & 35.549 & 16.695 & 8.347 \\
\hline 17.26 & 42.830 & 55.521 & 39.658 & 34.889 & 15.863 & 8.322 \\
\hline 23.03 & 34.477 & 47.555 & 35.666 & 30.910 & 14.266 & 8.111 \\
\hline 30.380 & 28.840 & 40.556 & 32.445 & 27.938 & 13.518 & 7.931 \\
\hline 44.100 & 21.730 & 32.905 & 29.801 & 22.351 & 12.417 & 7.450 \\
\hline 59.220 & 17.106 & 27.740 & 25.428 & 19.418 & 11.558 & 6.935 \\
\hline 77.920 & 14.055 & 22.840 & 21.428 & 16.866 & 10.190 & 6.324 \\
\hline 103.90 & 11.067 & 18.446 & 17.656 & 14.493 & 8.959 & 5.797 \\
\hline 137.10 & 8.986 & 14.979 & 14.378 & 11.982 & 7.189 & 4.92 \\
\hline
\end{tabular}

Egypt. J. Chem. 58, No. 4 (2015) 


\section{References}

1. Whistler, R.L. and Be Miller, J. N., "Industrial Gum", $3^{\text {rd }}$ ed., Academic Press Inc., New York, London, Tokyo p. 218-221.

2. Andrews, P., Hough, L. and Jones, J. K.N., J. Chem. Soc. 2744 (1952).

3. Andrews, P., Hough, L. and Jones, J.K.N., J. Chem. Soc. 74, 2029 (1952).

4. El-Molla, M.M., El-Halwagy, A.A., Salem, T.S. and El-Kashoti, M.A. $1^{\text {st }}$ International Conference of Textile Research Division NRC, Cairo, Egypt, March 2-4 105-111 (2004).

5. El-Kashoti, M.A., El-Molla., M.M., Salem, T.S. and El-Halwagy, A.A., Egypt, J. Chem., Special Issue (M. Kamel), 163-181 (2004).

6. El-Molla, M. M. Moussa, S.Z.A. and Ramaolan, Gh. S., Journal of the Textile Association Nov- Dec. 169 (2008).

7. El-Molla, M. M., Abd El-Rahman, A. A. and Abd El-Thalouth, I., American Dyestuff Reporter, 87 (9), 56-62 (1998).

8. El-Molla, M.M., American Dyestuff Reporter, 87 (10), 41-54 (1998).

9. Basu, T. and Charkraborty, M., Amer. Dyestuff Reptr, 80 (4), 42 (1997).

10. Cole, J. O. and Parks, C.R., Ind Eng. Chem. Anal. ed. 61, 18 (1946).

11. Hebeish, A., Abdel -Thalouth, I., Refai, R. and Ragheb, A., Starch. Starke, 41, 293 (1989).

12. El-Halwagy, A., A., El-Kashouti, M. A. and El-Molla, M.M., Tinctoria, 28, April (2002).

13. El-Molla, M.M., El-Halwagy, A.A. and El-Sayad, H.S., Journal of the Textile Association. 83-88 July - Aug. (2002).

(Received 26/12/2012; accepted $11 / 8 / 2015)$ 


\section{تصنيع و صفات كربامات صمغ الحلبة}

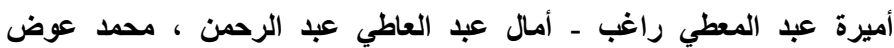

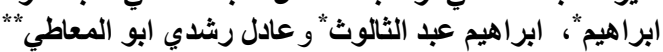

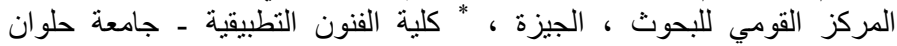

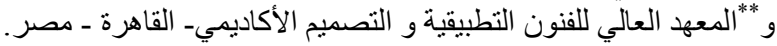

تم فصل صمغ الجالاكتومانان من البذور وتعريضها للتفاعل مع اليوريا في درجة

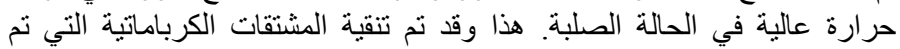

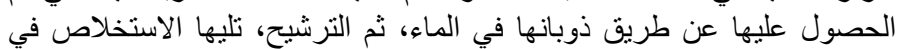

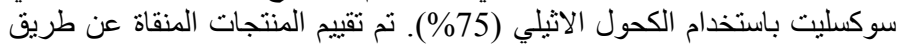

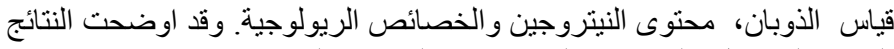

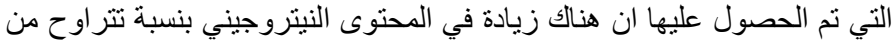

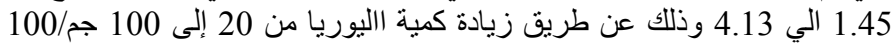

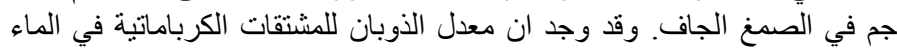

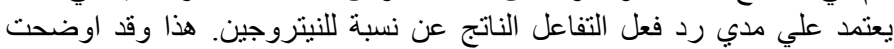

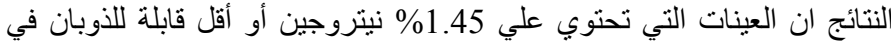

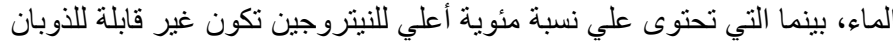

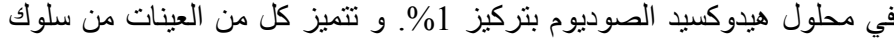

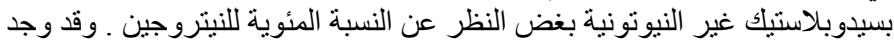

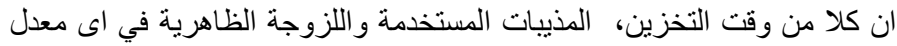

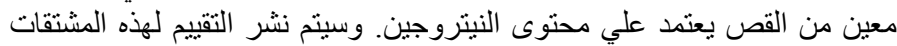
في طباعة المنسوجات في مقالات اخري. 